\title{
Tres reflexiones en homenaje a Mons. Oscar Arnulfo Romero
}

\author{
Luis Armando González
}

\begin{abstract}
En este mes de marzo, en el marco de la conmemoración del XXXVII Aniversario del asesinato de Mons. Romero- y en el marco del proceso de su proclamación como santo por parte del Vaticano- es importante reafirmar la actualidad de Mons. Romero en estos tiempos tan necesitados de referentes culturales y morales de envergadura. Se presentan aquí tres reflexiones que, además de la pretensión de reafirmar la vigencia su vigencia como referente moral y cultural para El Salvador, quieren ser un homenaje a ese gran patriota, pastor, hombre de fe y servidor de los humildes que fue Mons. Óscar Arnulfo Romero.
\end{abstract}

\section{Monseñor Romero, educador}

Definitivamente, marzo es el mes de Monseñor Oscar A. Romero. El Arzobispo asesinado el 24 de marzo de 1980 nos convoca siempre a reflexionar no sólo sobre su pensamiento y obra, sino a valorar y recuperar su legado, en una época distinta a la suya, pero con desafíos igualmente importantes e impostergables.

Ciertamente, de Monseñor Oscar Arnulfo Romero se pueden decir muchas cosas. Y la más radical es que Mons. Romero es lo más importante que le ha sucedido a El Salvador en el siglo XX. Peor para quienes no quieren o no pueden -por su ceguera ideológica o por su ignorancia- darse cuenta de ello. Peor para quienes no quieren o no pueden darse cuenta de lo terrible que fue su asesinato.

Pues bien, parte de la grandeza de Mons. Romero es que supo detectar con lucidez los problemas sustantivos de El Salvador y supo, a la vez, vislumbrar los caminos que llevarían a su solución. En esta línea, entendió que en el mar de problemas nacionales a enfrentar, la educación era, además de un desafío urgente a encarar, un camino para avanzar en la transformación de la realidad nacional. Mons. Romero se refirió una y otra vez a la educación en sus escritos y homilías. Una de las formas más bellas en que lo hizo es esta: 
"Que se capacite a los niños y a las niñas a analizar la realidad del país. Que los prepare para ser agentes de transformaciones, en vez de alienarlos con un amontonamiento de textos y de técnicas que los hacen desconocer la realidad. Una educación que sea educación para la participación política, democrática, consciente. Esto ¡cuánto bien haría! (30 de abril de 1978).

De una y mil maneras Mons. Romero insistió en que la educación debía preparar a los niños y las niñas, a los muchachos y las muchachas, para ser agentes de cambio social, familiar y personal. Es decir, que la educación debía estar volcada a atender, desde las exigencias del conocimiento, los problemas de la propia realidad.

El tratamiento temático de ello está esparcido a lo largo de la obra escrita de Mons. Romero y estuvo presente, una y otra vez, en su predicación. En este sentido, este el primer aspecto que hace de Mons. Romero un educador: reflexionó críticamente sobre la educación y sus desafíos, y nos legó un importante corpus escrito en torno a ello. No se le extraído a esta herencia toda la savia que contiene, pero esa savia está ahí a la espera de ser actualizada y puesta a producir.

En segundo lugar, Mons. Romero fue un educador porque promovió de manera decidida una educación inserta en la realidad, lo cual lo llevó a animar las obras educativas de distintas órdenes religiosas. Gracias a su impulso y exigencias, importantes colegios católicos dieron un giro en su forma de entender la educación, así como en su modo de entender quiénes eran los destinatarios de la misma.

La opción preferencial por los pobres se hizo presente en la praxis de instituciones nacidas para atender a la élite; estas instituciones llevaron a sus planes de estudio los problemas de la realidad nacional y trabajaron por romper con la alienación familiar y social de sus alumnos y alumnas.

Instituciones que, como la UCA y el Externado San José, habían sido pioneras en este esfuerzo de anclar la educación en la realidad encontraron en Mons. Romero- al Mons. Romero de la segunda mitad de los años setenta- a un defensor decidido.

En tercer lugar, Mons. Romero fue un educador porque dedicó sus mejores energías y talentos a educar a la sociedad salvadoreña, tanto a sus sectores populares como a su clase media, a sus militares, a sus políticos y sus oligarcas. 
La obra pastoral y teológica de Mons. Romero es una obra educativa de gran envergadura. Sus predicaciones en Catedral fueron, nunca mejor dicho, una cátedra permanente, en la cual el gran instrumento pedagógico fue la palabra firme, clara y verdadera.

Muy pocas veces como en boca de Mons. Romero la palabra viva ha tenido tanta fuerza y eficacia como recurso pedagógico. Comprensión, convencimiento, crítica, veracidad, operatividad, motivación, esperanza... Eso y más se encuentra presente en la palabra viva de Mons. Romero. Eso es lo que se echa de menos en el palabrerío que circula en boca de los manipuladores de la imagen que ocupan en la actualidad el espacio mediático.

En estos tiempos de predominio de la imagen, la palabra viva se ha devaluado. El proceso educativo mismo resiente la pérdida de sustancia de la palabra, cuando los recursos visuales la van desplazando del ejercicio del saber.

Es nefasto para la educación el lema hueco de que "una imagen vale más que mil palabras", porque en realidad una palabra bien dicha vale más que mil imágenes. Y no es que estas últimas no tengan valor: su valor, no obstante, depende las palabras con las que sean nombradas e interpretadas.

No ha habido en la historia contemporánea salvadoreña mejor maestro en esta materia que Mons. Romero. Supo usar las palabras correctas para nombrar e interpretar la realidad nacional y sus imágenes, por ejemplo aquellas que pretendían hacer de El Salvador "el país de la sonrisa" o que decían "paz, trabajo y amor en El Salvador", mientras que miles de niños morían por enfermedad o hambre, o los escuadrones de la muerte descuartizaban a los opositores políticos.

La palabra viva de Mons. Romero irradió conocimiento crítico y comprometido con la realidad, especialmente con la de quienes sufrían por la violencia estructural, institucional y terrorista. Pero no sólo fue un educador con la palabra viva; lo fue también con la palabra escrita, que supo dar en el blanco, con las fundamentaciones debidas, de los graves problemas de El Salvador.

Su producción escrita no sólo es amplia, sino densa en contenidos conceptuales, éticos, reflexivos y críticos. A la coherencia argumentativa, Mons. Romero añade la profundidad temática, en asuntos complejos y delicados que él supo clarificar con un dominio de la palabra escrita ciertamente excepcional.

Sus cartas pastorales y homilías son una fuente de enseñanzas invaluables para quienes deseen adiestrarse en el análisis de la realidad nacional. Pero sobre todo son una fuente en la que debe beber todo aquél que pretenda usar la palabra escrita para decir cosas que en verdad importen a la gente; para decir no banalidades y trivialidades, sino asuntos que tengan que ver con la vida y la muerte, la dignidad, la desesperación o la esperanza individual y colectiva. 
En definitiva, Mons. Romero fue y sigue siendo el gran pedagogo de la sociedad salvadoreña. Fue, es cierto, la voz de los sin voz, pero fue también quien educó a los que no tenían voz para que la tuvieran: dio voz a los sin voz. Por momentos, pareciera que quienes recuperaron su voz gracias a Mons. Romero no les preocupa renunciar a ella, no les preocupa quedarse de nuevo sin voz. Uno de los grandes desafíos de la transformación educativa que vive el país es que eso no suceda y que la sociedad salvadoreña se haga cargo de lo importante que es para su supervivencia no renunciar a la palabra, viva y escrita, que libera.

\section{II}

\section{Los valores de Mons. Romero}

Desde el asesinato de Monseñor Oscar Arnulfo Romero, el 24 de marzo de 1980, este mes se ha convertido, año con año, en un espacio para la reflexión, el recuerdo y la actualización del legado del Arzobispo mártir. Se trata de un legado, el suyo, rico en implicaciones de todo tipo: socio-políticas, históricas, educativas y morales. Es esta última dimensión del legado de Mons. Romero que quiero destacar en estas páginas.

Creo necesario y urgente reflexionar sobre los valores que Mons. Romero abanderó y que marcaron su desempeño como Arzobispo de San Salvador en los convulsivos años setenta hasta su muerte, en marzo de 1980. Que se entienda mi enfoque: no es una preocupación moralista o moralizadora la que me lleva a abordar el tema de los valores en Mons. Romero, sino una preocupación por el deterioro de referentes morales fundamentales que acusa nuestra sociedad, en sus diferentes ámbitos privados y públicos.

Y es que los valores de Monseñor Romero que me interesa destacar son esos valores fundamentales de su quehacer como pastor y como ciudadano consciente de sus obligaciones en un país atravesado por graves conflictos y desigualdades socio-económicas. No voy a repetir lo que se ha dicho en muchas ocasiones sobre su fidelidad a la verdad y su compromiso con la justicia, sino que voy a prestar atención a valores de los que poco que se habla, pero que son centrales para entender la magnitud de su figura moral.

a. Conciencia de las propias obligaciones ante los demás. Este es el primer valor que yo veo en Mons. Romero. Los valores son un asunto de conciencia, es decir, de convicción íntima acerca de lo que es bueno y malo, humano e inhumano. Poseer la convicción de que estamos obligados ante los demás -sus problemas, necesidades, miserias-constituye un valor de primera importancia. Un valor que Mons. Romero poseyó sin lugar a dudas y que se tradujo en una praxis de compromiso con los otros. 
b. La dignificación de los otros, especialmente de las víctimas de abusos de los poderosos. La obligación con los demás (con los otros) tuvo en Mons. Romero una clara dirección: trabajar por su dignificación, lo cual suponía un compromiso con su humanización. Mons. Romero privilegió, en su labor humanizadora, a quienes eran violentados en su humanidad por estructuras de poder injustas y excluyentes. No es otro el sentido de la expresión "opción preferencial por los pobres" que Mons. Romero -inspirado en Medellín y Puebla - hizo suya y tradujo a la realidad salvadoreña.

c. La búsqueda de coherencia entre la palabra y la acción. Nada más difícil que esa coherencia, sobre todo en los tiempos actuales cuando está de moda obrar de espaldas a lo que se predica. Mons. Romero se esforzó por hacer que su predicación sobre la dignificación de las víctimas no fuera sólo retórica, sino que su quehacer pastoral estuviera en sintonía con aquélla. Eso tuvo costos para él, siendo el mayor de ellos la pérdida de su vida. Y es que la coherencia entre palabra y acción, cuando ambas apuntan a lograr una mayor justicia, está mal vista por los poderosos de todos los tiempos. Por el lado contrario, la incoherencia es bien vista y, más aún, es fomentada a través del chantaje y los favores económicos y políticos.

d. Mirar la realidad del país desde quienes están en peor situación, es decir, desde las víctimas. Lo normal en la época de Mons. Romero (y en la nuestra) es que desde los círculos de poder económico, político y religioso la realidad se viera desde quienes estaban en la cima de la pirámide social. Mons. Romero hizo lo opuesto y desafió a los poderosos a que miraran a las víctimas y que desde ellas juzgaran al país que teníamos. Por supuesto que no lo hicieron; pero Mons. Romero lo hizo y su juicio fue severo: El Salvador estaba edificado sobre la miseria y la exclusión de la mayor parte de sus miembros. El país construido desde los intereses de los poderosos era un país inhumano.

e. Enjuiciar la realidad nacional con una palabra firme y clara. En nuestro tiempo otra de las modas es la ambigüedad en lo que se dice, no sólo para ser "políticamente correctos", sino para quedar bien con todos y que nadie pueda reprocharnos una expresión ofensiva o cuestionadora. En tiempos de Mons. Romero, la moda no era la ambigüedad en lo que se decía, sino la proclamación contundente de mentiras sobre la pobreza, la violencia y la injusticia. Mons. Romero, a sabiendas de que afirmar lo contrario a lo proclamado por los poderes de turno era peligroso, lo hizo. Sin ambigüedades, llamó a las cosas por su nombre y lo hizo de tal forma que todos entendieron lo que quería decir. 
f. Por último, no ambicionar poder y riquezas. No se tiene que perder de vista que Mons. Romero estuvo la cúspide del poder católico nacional. Desde ahí, el acceso a bienestar material, privilegios, bienes y demás cosas que simbolizan una vida placentera estaban al alcance de su mano. Lo más fácil y que pocos hubieran visto mal era optar por los privilegios del cargo y trabajar por escalar más en la jerarquía de poder eclesial internacional. Pero este buen hombre no hizo eso; no pensó que tener riquezas, privilegios y poder fueran una opción de vida para él.

No sé cómo verán a Mons. Romero quienes creen que lo que se tiene que buscar en cualquier cargo público es la acumulación de riquezas, pero desde un punto de vista ético su lección es mayúscula: envidiar a los ricos y querer ser como ellos no es bueno ni recto, pues eso es una bofetada a quienes -una mayoría de salvadoreños - viven en la miseria y en la exclusión.

En definitiva, Mons. Romero fue un hombre de sólidos valores humanos y humamizadores. Los valores de él que he destacado nos son ajenos o por lo menos sólo son cultivados por un puñado de gente de buena voluntad, gente a la que se suele ver como idealista, ingenua y al margen del pragmatismo imperante hoy en día. Sin embargo, de lo que se trata es de reivindicarlos como algo necesario para construir una mejor sociedad, en la cual el oportunismo y el aprovecharse de los demás sea algo inaceptable en la conciencia de cada cual.

III

\section{Actualidad de Mons. Romero}

El siglo XXI avanza rápido no sólo en términos cronológicos, sino en términos económicos, sociales, culturales y medioambientales. Cambios de distinta índole su suceden por doquier; la llamada "sociedad líquida" pareciera haberse impuesto definitivamente. Vivimos, pues, unos "tiempos líquidos" en los cuales la fugacidad de los acontecimientos, más que su estabilidad y permanencia, es lo más normal en la vida de las personas.

La cultura actual, la cultura predominante, es la que mejor expresa y refuerza esta dinámica de cambio permanente. El "ir de prisa" en pos del éxito fácil es su marca más característica. Nunca como en nuestra época se valora tanto la rapidez y se desprecia en igual medida la lentitud. Pararse, detenerse, hacer un alto, tomar distancia... Nada peor que esto para frenar el ritmo de los procesos, el ritmo de la cotidianidad, el ritmo de los comportamientos y decisiones.

De aquí el movimiento incesante de personas y cosas, de opiniones, modas y gustos. Quien más se mueve, quien avanza más de prisa que los demás, alcanzará antes que ellos y ellas cualquier meta pero, después de todo, la meta es lo de menos, porque la misma también es algo volátil, algo que una vez que se alcanza pierde sentido al ser obsoleto ante aquello que lo ha desplazado. 
En la sociedad líquida, así como unas personas desplazan a otras, al ir más rápido que ellas, unas cosas desplazan otras (como sucede con los nuevos modelos de teléfonos celulares que desplazan incesantemente a los antiguos, que eran “nuevos" apenas ayer). Este estar en viviendo en velocidad, de prisa, desplazando a quienes aparecen en el camino como un obstáculo a vencer, erosiona la convivencia social, al introducir prácticas agresivas y violentas en las relaciones sociales. Este es el efecto inmediato y cotidiano del ir a toda prisa haca cualquier parte.

Pero hay otros efectos de mediano y largo plazo. Uno de los más graves es la pérdida de perspectiva de lo que es importante y de lo que es secundario en la realización personal, familiar y social. Lo más inmediato y fácil se convierte en lo más importante. Los proyectos que exigen miradas de largo plazo, compromisos y disciplina se pierden de vista. El ahora es lo único que cuenta.

Se pierde de vista la solidaridad y la cooperación, sin las cuales una sociedad decae en la anomia y la pérdida de sentido de sus miembros. En una sociedad en la que "llegar primero" es lo más valorado, quienes se rezagan son despreciados, son vistos como "perdedores" y "fracasados". Lo cual quiere decir que no deben ser objeto de atención y protección, sino de rechazo y condena.

En una visión competitiva de la vida, como la que alimenta la cultura neoliberal, el bien común y la opción por las víctimas brilla por su ausencia. Cuenta el éxito propio, que se ostenta y se publicita para que no quede dudas de quién ha ganado en la competencia social y económica.

En fin, la cultura de lo vertiginoso, la cultura del vértigo producido por el cambio incesante en las relaciones personales y en las cosas, tiene una fuerte presencia en las sociedades actuales. Marca los comportamientos y las prácticas sociales, generando graves daños al tejido social.

¿Podemos encontrar algo en Mons. Romero que nos ayude a plantarnos de otra manera ante esta cultura de lo líquido, lo inmediato y lo fácil?

Por supuesto que sí. Hay muchas ayudas para ello en su labor pastoral y en su obra político-teológica. Mencionemos tres.

La primera es la de hacer los necesarios altos en el camino para tomar distancia de los acontecimientos y no dejarnos arrastrar por ellos. Cuánta falta hace en la conciencia ciudadana el hábito del "alto en el camino" y la meditación acerca de cómo se está parado en la realidad. 
No tomar una mínima distancia de los acontecimientos y no meditar sobre nuestras acciones, supone ser arrastrados por dinámicas en las cuales deberíamos intervenir. Mons. Romero manejó con maestría el hábito de la toma de distancia, el alto en el camino y la meditación sobre las propias acciones.

La segunda ayuda que nos puede dar Mons. Romero es la de ensañarnos a establecer prioridades en nuestra vida, pero no cualesquiera prioridades, sino aquellas que ponen en primer lugar la dignidad de las personas, y principalmente de las más débiles y vulnerables. Definitivamente, no todo da igual en la vida de las personas; no todos las metas personales y sociales son equivalentes.

Hay metas más importantes que otras, y entre las primeras -como enseñó Mons. Romero- las que cuentan son aquellas que hacen que la vida y dignidad de los pobres y desposeídos sea menos miserable.

Y en tercer lugar, Mons. Romero también nos enseña que el éxito fácil, simbolizado en riqueza y ostentación, no es una aspiración que debe ser fomentada socialmente, sino que al contrario debe ser contenida y criticada. Y es que si se la deja florecer sus efectos son nocivos para la sociedad, por las dinámicas de abuso, desprecio y agresividad que genera entre sus miembros.

En Mons. Romero hay una ética cívica de la cual casi nadie habla, pero que es invaluable en un país como este, tan erosionado moralmente.

He mencionado apenas tres aspectos de esa ética cívica, pero no cabe duda que en la obra de Mons. Romero hay muchos más elementos en ese rubro que están a la espera de ser destacados y puestos al servicio de un cambio moral-cultural en El Salvador. 